Schuster/Grützmacher · IT-Recht Kommentar 



\section{IT-Recht Kommentar}

EU-Recht $\cdot$ Nationales Recht Besondere Vertragsbedingungen

herausgegeben von

Prof. Dr. Fabian Schuster

Rechtsanwalt und

Fachanwalt für IT-Recht, Düsseldorf

Honorarprofessor

an der Universität zu Köln

Dr. Malte Grützmacher, LL.M. (University of London)

Rechtsanwalt und

Fachanwalt für IT-Recht, Hamburg

2020

\section{ottoschmidt}


